\title{
Control of infectious disease during pregnancy among pastoralists in South Sudan: A case for investment into mobile clinics
}

\author{
Emmanuel Nene Odjidja(1)
}

\begin{abstract}
Given their high intermittent mobility, proximity to cattle as well as underlying cultural practices, pastoralists are among groups with high exposure to infectious diseases. Living under adverse environmental conditions while in search for pasture can result in malaria and other environmental pathogenic diseases. Proximity to cattle and consumption of raw untreated milk from cows result in Treponema infections and bovine TB. Furthermore, widespread practice of polygamous relations increases the risk of sexually transmitted infections. Compounded with this, especially in humanitarian crisis settings with weaker health systems, pregnant pastoralists are under-served resulting in an escalation of the impact of infectious diseases which affects pregnant women and their developing foetus via vertical transmission. Using South Sudan as a case study, this paper argues that it is essential to control infectious diseases among pregnant pastoralists, through exploring various ambulatory health services especially mobile clinics. In addition, the paper calls for an increased investment into mobile clinics for pregnant pastoralists as a way of achieving global responsibility of ensuring universal health coverage.
\end{abstract}

Keywords: Infectious disease, Humanitarian, Mobile clinics, Pregnancy, South Sudan, Pregnant pastoralist

\section{Introduction}

Infectious disease during pregnancy remains a public health problem that affects pregnant women and the developing foetus. At pregnancy, pre-acquired infections are either reactivated or escalated due to partial immunity. This increases the risk of pregnancy-related complications which could eventually result in maternal and/or neonatal mortality if undetected and treated at early stages. Globally, an estimated 75,750 pregnant women (25\% of all maternal mortality) die from complications of human immunodeficiency virus (HIV), malaria and tuberculosis infections; 90 percent of which occur in resource-limited settings in sub-Saharan Africa (Patton et al. 2009). In high-burden infectious disease settings, the World Health Organization recommends comprehensive screening and prompt treatment of infectious diseases:

Correspondence: emmaodjidja@gmail.com AVSI Foundation, Torit, South Sudan malaria, tuberculosis, HIV and hepatitis during ante-natal care sessions (World Health Organization 2018).

South Sudan, the world's newest nation, ceded from main Sudan in 2011. However, it currently ranks number five on the countries with highest rates of maternal mortality. Estimates show that maternal mortality stands at 789 per 100,000 with only $17.2 \%$ deliveries supervised by skilled birth personnel (World Health Organization 2016). In the face of these devastating maternal health outcomes, neonatal and infant health has also been affected. The World Health Organization (2016) estimates that South Sudan presently experiences neonatal and infant mortality 39.3 per 1000 and 99.6 per 1000 respectively (World Health Organization 2016). Direct causes of maternal mortality in South Sudan, just like other sub-Saharan African countries, have been attributed to haemorrhage, eclampsia and obstructed labour along with a significant indirect causes of infectious diseases, namely malaria, hepatitis and HIV (Ahmed and Abdel-Rahman 2008). 
To reduce the impact of infectious disease among pastoral infants and pregnant women, this project holds the theory of change that if we understand how pastoralists move seasonally across the Kapoeta County of South Sudan, we could administer integrated preventive mechanisms to mitigate the impact of these diseases. For this reason, the Phase 1 of this project focused on understanding the pastoralists' cultural practice,s including their movement patterns, along with a general background understanding. This was followed by a series of activities with local health authorities to model possible interventions for ambulatory services. In the second phase, mobile clinics were selected as the most cost-effective intervention, which was implemented. Services offered in a mobile clinic include vaccinations for infants (as recommended by the South Sudanese Expanded Programme on Immunization). Pregnant women receive prompt screening of malaria, TB, HIV and hepatitis, and if declared positive, they immediately undergo treatment. Given that most of these diseases need long-term management, we monitor monthly based on where the patients are located. Furthermore, for malaria, the project allocates malaria prophylaxis (intermittent preventive treatment) as recommended by the World Health Organization.

\section{Study area}

Kapoeta State has generally limited vegetation comprising short grasses and shrubs. Around remote areas of Kapoeta, however, there is thicker vegetation which makes it a preferred destination of most pastoralists, even in Kapoeta South (Narus). January is the driest month with an average of $7 \mathrm{~mm}$ of rain. In comparison, July has the wettest month with an average $96-\mathrm{mm}$ rain. Temperatures are almost homogeneous throughout the year ranging from 27.8 to $24.3{ }^{\circ} \mathrm{C}$. Kapoeta is mostly inhabited by the Toposas (a traditional tribe related to the Turkana in Kenya) who are predominantly cattle herders with a smaller proportion of farmers. The Toposa people mainly farm maize and millet. In recent times, the upsurge of mining activities on the main Narus road (Kapoeta South) is seeing a significant proportion of people joining this activity. There have been large proportions from as far as Kapoeta North settling in the areas of Narus. After the 2013 conflict, however, Kapoeta has become a trade hub connecting traders from Ethiopia, Uganda and Kenya. As such, there have been a growing number of traders in all areas of Kapoeta. This trend has resulted in many traders of cattle, which hitherto was unknown in this area (Figure 1).

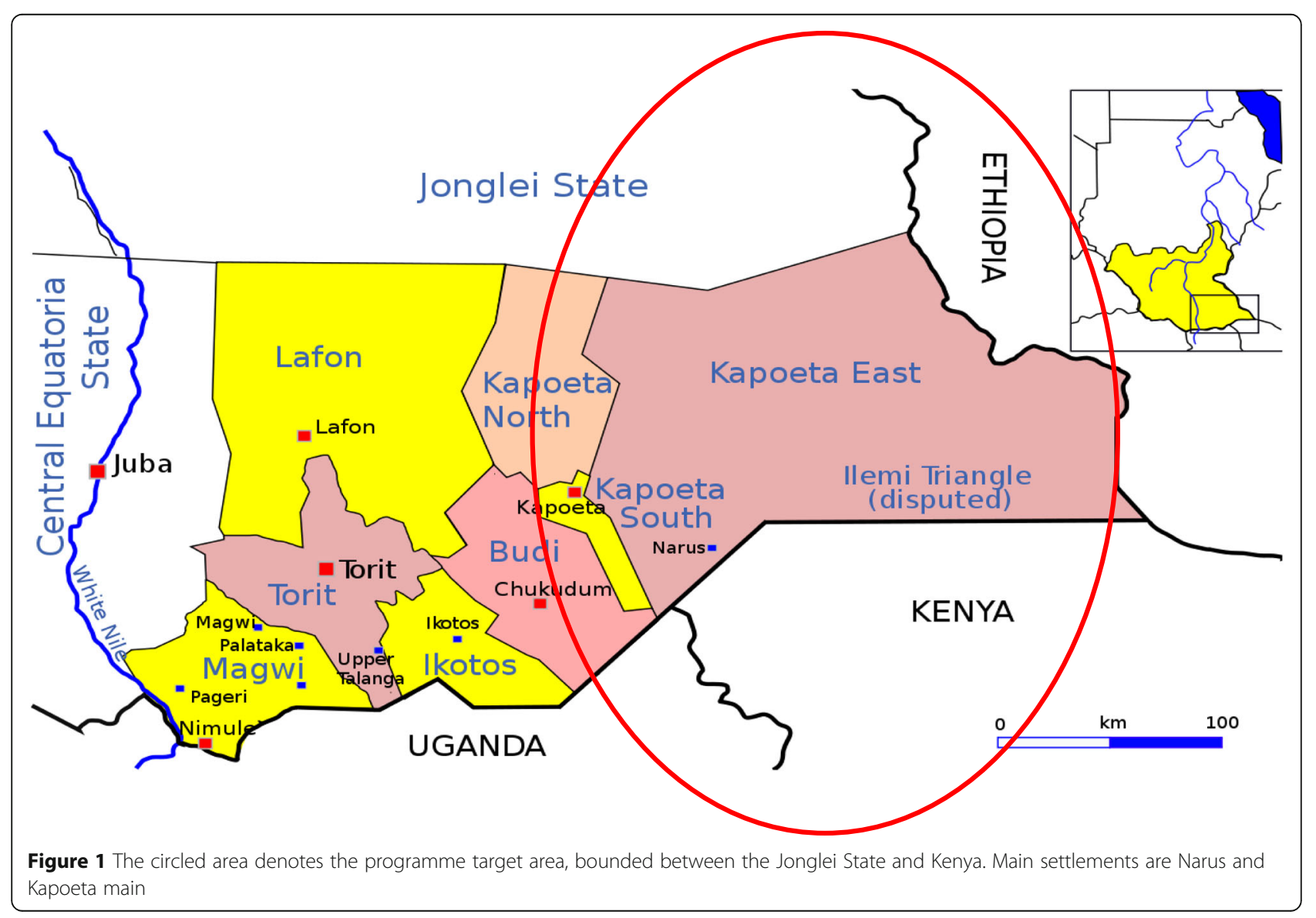




\section{An outlook on the culture and ongoing conflict in Kapoeta}

Toposas are a Nilo-Hamitic agro-pastoral territory which spans from Jie, Didinga, Donyiro and Kenya's Turkana population (Springwood 2007). Their main economic activity revolves around livestock herding, including cattle, goats, sheep and, to a lesser extent, donkeys. Measures of wealth in Toposaland are dependent on two indicators: cattle ownership and possession of loaded guns (Springwood 2007). There were polygamous families with $84.8 \%$ reported additional wives in the household (AVSI Foundation South Sudan 2017). In this context, marriage to a number of women is associated with a man's social status in this society; thus, the number of wives could be used as a proxy for socio-economic status (Roth and Kurup 1990; Nyamilepedia 2016). Furthermore, there exists a disparity between the average number of women and children. This is as a result of the fact that additional women translate into net economic gain as they are exclusively responsible for agricultural cultivation (Roth and Kurup 1990). Wives are mainly responsible for farming, caring for the elderly and cooking. In fact, women are expected to be breadwinners of the household. On the other side, men's roles include grazing and providing defence for the cattle (Figure 2).

Toposa people have a longstanding conflict with the people of Budi (who are also pastoralists). From history, these two groups have engaged in several periodic cattle raids resulting in sporadic conflicts among communities. Although these two groups signed a peace agreement in 2005 , they re-engaged in an intensified conflict after a group of Toposa men attacked some Budi communities in 2007. This claimed 54 lives including 48 women (Nyamilepedia 2016). Aside from cattle raiding being the main cause of conflicts between the Budi and Toposa, other causes have been cited. Maystadt et al. (2014) postulates that increasing temperatures resulting in limited grassland further triggers conflicts among these groups as their cattle have smaller areas of grassland to feed on. In 2013 however, they reached an amicable agreement with the promise to end violence. This was followed with another conference in 2014 and this saw an end to hostilities among these groups, although there have been smaller intermittent attacks from both sides in pockets of places in Kapoeta and Budi (Nyamilepedia 2016).

\section{Methods}

\section{Study design}

This was a cross-sectional study of 295 pastoral women sampled to understand the social issues surrounding health and health-seeking behaviour. As pastoralists have an irregular movement pattern, the first stage design employed a rapid assessment to understand the place of residence at that time, then together with their local chiefs, this followed establishing contacts (using a snowball technique) and administering surveys as well as delivering control of infectious disease services using the mobile clinics. The main focus of disease prevention were rapid diagnostic screening and routine prevention of mother-to-child HIV transmission (PMTCT) services if detected positive. For malaria services, pregnant women received rapid screening for malaria and, if in the first 16 weeks of pregnancy, an intermittent preventive treatment for malaria using sulpha-doxine pyrimethamine (SP) on a monthly

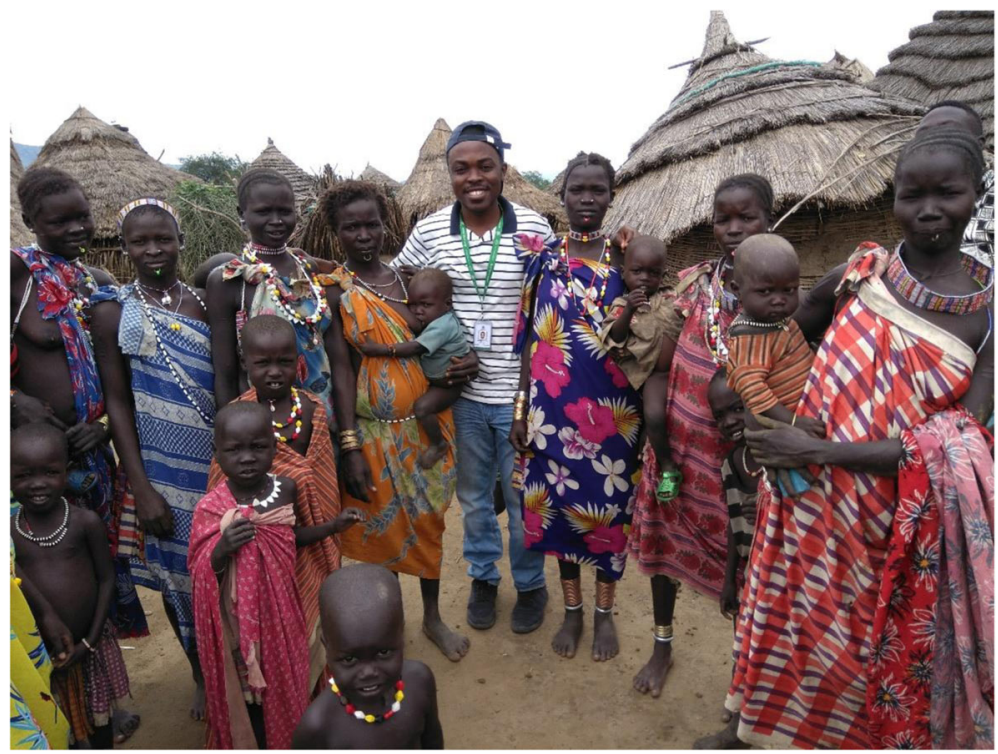

Figure 2 Field visit to Toposa women during evaluation data collection 
basis. Consent by participants was sought to engage in the project and both the baseline and evaluation stages.

\section{Data collection}

A team of four visited tempory places where pastoralists were located. This team was made up of a nurse, two clinical assistants and a data assistant. At that point, the team administered questionnaires which included a history of health services received since becoming pregnant or during the last birth delivery. The team then screened the participants, using rapid diagnostic tests, and results were entered into the electronic mobile-based system Kobotoolbox. This process was repeated on a monthly basis for 6 months and followed with an evaluation.

\section{Data analysis}

Data was downloaded from Kobotoolbox in the form of Excel and analysed into SPSS version 20. Background statistics was obtained from these women including their pregnancy status. The baseline on doses of malaria prophylaxis and screenings for HIV was compared to the endline with a significance level determined to examine the difference between pre- and post-intervention results. Significance was pegged at $0.05(p \leq 0.05)$.

\section{Results}

Of the 295 women sampled for the baseline and endline, $82(28 \%)$ were pregnant and $43(14.6 \%)$ were lactating. Eighty-two percent of all women were in polygamous relationships with an average of 6 children each. Women Women who previously had a baby and currently not pregnant (170 women) received routine ante-natal care services from fixed health facilities (Table 1).

In pastoral women who are currently pregnant (82 women), the receipt of essential infectious disease control followed the same trend. However, this increased at the endline which was six months after implementing the mobile clinics. An average of four doses of monthly malaria prevention were administered to women at the end of the project implementation (Table 2).

Table 1 Results of women who received infectious disease control services received from fixed health centres

\begin{tabular}{ll}
\hline Women with no pregnancy & \% at baseline \\
\hline $\begin{array}{l}\text { Proportion of women who received any form of } \\
\text { malaria screening during recent pregnancy }\end{array}$ & $(24) 14.1 \%$ \\
Proportion of women received tablets for malaria & $(15) 8.9 \%$ \\
prevention & \\
Receiving HIV screening during recent pregnancy & $(20) 11.8 \%$ \\
Among screened and tested HIV-positive, proportion & (2)5.8\% \\
that received ART to prevent transmission & \\
\hline
\end{tabular}

\section{Discussion}

Among pastoralists, the manifestation of infectious diseases in pregnancy is much worse, and results in poor maternal health outcomes which are higher than the general population in South Sudan. According to the main Sudan census, maternal mortality among pastoralists is $33.1 \%$ higher than the rest of the population (Ahmed and Abdel-Rahman 2008). An explanation of this trend has been attributed to a number of reasons, ranging from inherent social cultural issues (Dyson-Hudson and Dyson-Hudson 1980) and health system issues similar to other humanitarian crisis settings that discourage ante-natal care (ANC) attendance during pregnancy (Leslie and Fry 1989). Culturally, pastoralists associate increased female births with economic gains and higher societal status, which implies lower use of family planning methods and poor spacing of pregnancies (Leslie and Fry 1989). In addition, there is a high prevalence of female genital mutilation among pastoralists, thereby increasing risks of pregnancy complications especially during delivery (Montavon et al. 2013). Female genital mutilation (FGM) together with other socio-cultural factors such as high poverty prevalence, low education and giving birth at a young age, results in increased cases of obstetric fistula. According to the World Health Organization (2016), obstructed labour globally accounts for $6 \%$ of maternal morbidity and mortality and affects between 500,000 and $1,000,000$ women.

Regarding the South Sudanese health system, although the Ministry has adopted a primary health approach, there are prevailing challenges of health financing, limited staff versus high demand for health services, poor infrastructure and general functioning of health services. In addition, there is generally lower utilisation of health services by pastoralists due to their seasonal movements (El Shiekh and van der Kwaak 2015). This irregular movement pattern affects their use of health services as they move nearer or farther away from the existing limited health services. Movement of pastoralists in South Sudan, just as those in many places of the world, is determined by water and pasture (Mugo et al. 2015). For those who are pregnant, this irregular movement has several implications which affect their health and overall well-being. First, proximity to the livestock during these movements increases risk of transmission of some infectious and zoonotic diseases such as Treponema infections, diarrhoea and malaria. Second, dietary practices such as consumption of raw untreated milk and meat from livestock during these movements could increase the risk of brucellosis and bovine tuberculosis (TB) (Dyson-Hudson and Dyson-Hudson 1980). Polygamous sexual relations/marriages among pastoralists increase the risk of HIV and other sexually transmitted diseases. In fact, according to the South Sudan Ministry of 
Table 2 Results of women who received essential infectious disease control services before and after project implementation

\begin{tabular}{|c|c|c|c|}
\hline Women currently pregnant & $\%$ at baseline & $\%$ at endline & $p$ value \\
\hline Proportion of women who received any form of malaria screening during this pregnancy & $(11) 14.1 \%$ & $(73) 89.6 \%$ & 0.03 \\
\hline $\begin{array}{l}\text { Proportion of women received tablets for malaria prevention (for those more than } 16 \text { weeks } \\
\text { of pregnancy - } 49 \text { women) }\end{array}$ & (5) $10.2 \%$ & $(47) 95.9 \%$ & 0.01 \\
\hline Proportion of pregnant women who owned a mosquito net & (3) $3.6 \%$ & (78)95.1\% & 0.01 \\
\hline Receiving HIV screening during recent pregnancy & $(13) 15.9 \%$ & $(69) 84.1 \%$ & 0.04 \\
\hline $\begin{array}{l}\text { Among screened and tested HIV-positive, proportion that received ART to prevent transmission } \\
\text { (Eye Radio Network 2018) }\end{array}$ & (5) $17.6 \%$ & (15)88.2\% & $<0.01$ \\
\hline
\end{tabular}

Health, the highest incidences of HIV are found at Kapoeta State which is largely dominated by pastoralists and semi-pastoralists (Leslie and Fry 1989). In our multi-sector evaluation to understand pastoralists' fabric of life in Kapoeta, we found that men had an average of four wives (Montavon et al. 2013). These marital practices vis-à-vis low ANC attendance could increase risk of HIV vertical transmission from mother to child.

To more effectively control infectious diseases and prevent vertical transmission of infectious disease in pregnancy among these geographically unstable populations, investing in mobile community-based interventions, especially mobile clinics, could be beneficial. Delivery of integrated infectious disease control services via mobile clinics for continuous moving pastoralists has been proven as a more cost-effective intervention than fixed-location health facilities (El Shiekh and van der Kwaak 2015). In rural Mozambique, the implementation of mobile clinics resulted in an increased number of anti-retroviral treatments (ART) among pregnant women especially in hard-to-reach areas (Mugo et al. 2015). Likewise, in Chad, in response to the polio outbreak in 2012, the government adopted mobile clinics for the nomadic population, which resulted in an increased vaccine coverage from a previous 0 to $93.6 \%$ (Weibel et al. 2008). In Mongolia, the implementation of mobile clinics for hard-to-reach populations in the rural areas has proved not only to increase coverage of relevant services but is highly cost-effective in comparison to fixed location facilities (Mocellin and Foggin 2008).

\section{Conclusion}

Towards realisation of the 2030 Sustainable Development Goal (SDG) agenda, new health systems approaches and strategies must be adopted to ensure equity for less privileged populations like pastoralists, especially for those humanitarian settings where the ineffectiveness of the health system is apparent. Pregnant pastoralists/nomadic women remain less targeted, although their irregular movements, exposure and socio-cultural practices threaten their health and that of their unborn babies. Targeted research into their fabric of life including health-seeking behaviours would offer a thorough understanding of their health needs, thereby pursuing an efficient yet cost-effective mobile health system that would deliver integrated infectious disease control services to these women. Indeed, in the principles of universal health coverage, attention should be channelled towards these women whose efforts and needs usually go unnoticed.

\section{Abbreviations}

ANC: Ante-natal care; ART: Anti-retroviral treatment; FGM: Female genital mutilation; HIV: Human immunodeficiency virus; SDG: Sustainable development goal; TB: Tuberculosis

\section{Funding}

This project was funded by the Italian Agency for Development Cooperation.

\section{Author's contribution}

ENO conceptualised the whole idea and wrote and reviewed the entire manuscript. The author read and approved the final manuscript.

\section{Ethics approval and consent to participate}

Ethical clearance was granted for the entire project design and implementation including this study by the South Sudanese Ministry of Health. All participants of this study granted consent to participate and fully understood that results of this study could be published.

\section{Consent for publication}

All participants in the images displayed in the manuscript agreed as well as granted approval for their wards to be shown in the manuscript as well.

\section{Competing interests}

The author declares that he has no competing interests.

\section{Publisher's Note}

Springer Nature remains neutral with regard to jurisdictional claims in published maps and institutional affiliations.

Received: 15 July 2018 Accepted: 14 August 2018

Published online: 25 September 2018

\section{References}

Ahmed, N., and N. Abdel-Rahman. 2008. Demographic and socio-economic characteristics of nomadic population/Sudan fifth census. Sudan office of statistics; Khartoum. (non-published report). https://scholar.google.com/ scholar?hl=en\&q=Ahmed\%2C\%20N.\%20and\%20Abdel-Rahman\%2C\%20N. \%202008.\%20Demographic\%20and\%20socioeconomic\%20characteristics\%20 of\%20nomadic\%20population\%2FSudan\%20fifth\%20census.\%20Khartoum. \%20\%28nonpublished\%20report\%29.

Association of Volunteers in International Service (AVSI) Foundation South Sudan. 2017. Multi-sector Study of Pastoralists in Kapoeta State of South Sudan. Kapoeta Main: AVSI Foundation, South Sudan.

Dyson-Hudson, R., and N. Dyson-Hudson. 1980. Nomadic pastoralism. Annual Review of Anthropology 9 (1): 15-61.

El Shiekh, B., and A. van der Kwaak. 2015. Factors influencing the utilization of maternal health care services by nomads in Sudan. Pastoralism 5 (1). https:// doi.org/10.1186/s13570-015-0041-x. 
Eye Radio Network. 2018. Gbudwe and Kapoeta record highest HIV prevalence in 2016. [online] Available at: http://www.eyeradio.org/gbudwe-kapoetarecords-highest-hiv-prevalence-2016/. Accessed 17 May 2018.

Leslie, P.W., and P.H. Fry. 1989. Extreme seasonality of births among nomadic Turkana pastoralists. American Journal of Physical Anthropology 79 (1): 103-115.

Maystadt, J.F., M. Calderone, and L. You. 2014. Local warming and violent conflict in North and South Sudan. Journal of Economic Geography 15 (3): 649-671.

Mocellin, J., and P. Foggin. 2008. Health status and geographic mobility among semi-nomadic pastoralists in Mongolia. Health \& Place 14 (2): 228-242 Available at: http://www.ncbi.nlm.nih.gov/pubmed/17683967.

Montavon, A., V. Jean-Richard, M. Bechir, D.M. Daugla, M. Abdoulaye, R.N. Bongo Naré, and J. Zinsstag. 2013. Health of mobile pastoralists in the Sahel-assessment of 15 years of research and development. Tropical Medicine \& International Health 18 (9): 1044-1052. https://doi.org/10.1111/tmi. 12147 Available at: http://www.ncbi.nlm.nih.gov/pubmed/23834073. Accessed 31 Mar 2018.

Mugo, N.S., M.J. Dibley, and K.E. Agho. 2015. Prevalence and risk factors for nonuse of antenatal care visits: Analysis of the 2010 South Sudan household survey. BMC Pregnancy and Childbirth 15 (1): 68.

Nyamilepedia. 2016. Toposa of Kapoeta East County declared war on the people of BUDI County. [online] Available at: http://nyamile.com/2016/06/05/toposa-ofkapoeta-east-county-declared-war-on-the-people-of-budi-county/. Accessed 11 Aug 2018

Patton, G., C. Coffey, S. Sawyer, R. Viner, D. Haller, K. Bose, T. Vos, J. Ferguson, and C. Mathers. 2009. Global patterns of mortality in young people: A systematic analysis of population health data. The Lancet 374 (9693): 881-892.

Roth, E.A., and K.B. Kurup. 1990. Polygyny as social and biological differentiation among Toposa agro-pastoralists of Southern Sudan. Social Indicators Research 22 (4): 385-398.

Springwood, C.F., ed. 2007. Open fire: Understanding global gun cultures. Oxford: Berg.

Weibel, D., E. Schelling, B. Bonfoh, J. Utzinger, J. Hattendorf, M. Abdoulaye, and J. Zinsstag. 2008. Demographic and health surveillance of mobile pastoralists in Chad: Integration of biometric fingerprint identification into a geographical information system. Geospatial Health 3 (1): 113-124.

World Health Organization. 2016. World health statistics 2016. Geneva: World Health Organization.

World Health Organization. 2018. New quidelines on antenatal care for a positive pregnancy experience. [online] Available at: http://www.who.int/ reproductivehealth/news/antenatal-care/en/. Accessed 4 Dec 2017.

\section{Submit your manuscript to a SpringerOpen ${ }^{\circ}$ journal and benefit from:}

- Convenient online submission

- Rigorous peer review

- Open access: articles freely available online

- High visibility within the field

- Retaining the copyright to your article

Submit your next manuscript at $\boldsymbol{\nabla}$ springeropen.com 